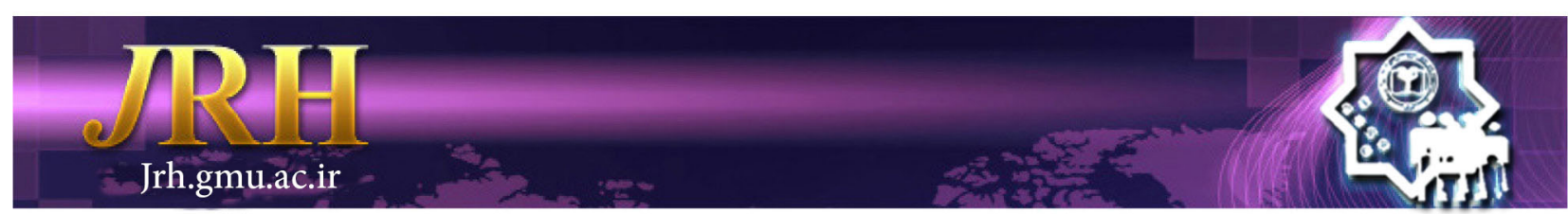

\title{
Effect of spiritual family therapy on marital satisfaction in couples with husbands' drug-dependent
}

Masoud Khakpour ${ }^{1}$, Masoomeh Mehrafarid ${ }^{2}$, Hosein Akbari

Amarghan $^{2}$, Hamid Nejat ${ }^{2}$, Maryam Fazayeli Yousefabad ${ }^{2}$, Roya Toroghi $^{2}$

\author{
Journal of Research \& Health \\ Social Development \& Health Promotion \\ Research Center \\ Vol. 8, No. 4, Jul \& Aug 2018 \\ Pages: $365-372$ \\ DOI: $10.29252 /$ jrh.8.4.365 \\ Original Article
}

1. Correspondence to: Department of Psychology, Hakim Nezami Institute of Higher Education, Quchan, Iran

Email: m.khakpour54@gmail.com

2. Department of Psychology \& Counseling, Azad University of Quchan Branch, Quchan, Iran

Received: 25 Jan 2016

Accepted: 20 Feb 2018

How to cite this article: Khakpour $\mathrm{M}$, Mehrafarid M, Akbari Amarghan $\mathrm{H}$, Nejat $\mathrm{H}$, Fazayeli Yousefabad M, Toroghi R. Effect of spiritual family therapy on marital satisfaction in couples with husbands' drug-dependent. $J$ Research Health2018; 8(4): 365- 372.

\begin{abstract}
Addiction and Problematic drug use, led to the physical, psychological, social and family destruction especially clinically significant or serious discomfort. This study aimed to efficacy of spiritual therapy based on family-centered on marriage satisfaction in couples with husbands' drug-dependent. This design was a quasi-experimental. The population consisted all drug-dependent and their wives in Quchan (prisoners and patients referred to the clinics withdrawal). 40 couples volunteered to participate in this study and were placed randomly in the experimental group (20 couples) and control group (20 couples). Participants reply to afrooz marital satisfaction scale. Couples in experimental group received 10 sessions of 90 minutes spiritual Family therapy and the control group received no intervention. Analysis of covariance showed that the differences between pretest and posttest of marital satisfaction in experimental group and all its sub-tests that increased significantly in the experimental group, while no significant changes in control groups. Also there were significant differences in marital between the experimental group and the control group. So spiritual therapy based on family-centered on marital satisfaction of couples were effective. Spiritual therapy based on family-centered could improve their marital satisfaction Couples with husbands' drug-dependent and effected on increasing of marital satisfaction of couples involved in addiction that shows abnormal patterns of family relationships. The results can be the aimed to family-based treatment and harm reduction interventions at preventing relapse and reduce craving in substance abusers and can be used re-examining it.
\end{abstract}

Keywords: Addiction, Couple, Satisfaction, Spiritual, Therapy

\section{Introduction}

Drugaddiction, with the physical, psychological, social, and familial aspects is one of the most important problems of our time. As far as this problem has been worldwide [1].

Addiction is problematic pattern of substance use leading to clinically significant or discomfort with at least two of the following, occurring within a 12-month period: (high consumption andlong-term, constantdesireand unsuccessful attempts to cut down or control use, time good for consumption, material preparation and release of its effects, craving and feeling the need to use, failure to perform the main duties of the individual in work, school and home, 
social or interpersonal problems, recurrent or persistent influence of material, reduced important activities social, occupational or recreational use of the substance in situations that are physically dangerous, continuing to use the substance despite knowledge of physical or mental problems continued, tolerance or need for increased amounts of substance to achieve the desired effect of reducing specific effects of the continued use of the same amount before the withdrawal) [2].

Addiction is one of mental health catastrophic situation for addicts or those who are in direct contact with the addicted person (family members) that it reduces the ability, social role and they failed in the face of difficult situations and they do not have the necessary flexibility. Addiction itself can cause mental illness, so that studies have been reported the prevalence of psychiatric disorders among drug users between 25 to 80 percent. So stress can cause more mental disorders other family members [3].

The family has a basic role in people's health and disease. Theories and many researchers have confirmed family influences in the formation of concepts of health and disease and model of normal and abnormal behavior. The family is the most important and influential factor in health systems, therefore requires special attention [4]. Family is first place in developing personality, beliefs and behavior patterns in a person. In addition to the growth and preservation of the family and help solve stress and disease and disorder is also a source of stress [5]. In fact, in a vicious cycle, the material changes in the relationship and conflict between members, then these changes and stressful conflicts, to act as an agent in order to prolong drug [6].

Family plays a major role Incidence, persistence and survival of pathological symptoms including substance abuse $[4,7,8]$. When a family member has pathological symptoms, there is some trouble imbalance in functions and family interaction patterns are organized around that problem [9].

Living in families with drug abuse and drug dependence created psychological pressure and family members tries to deal with it in different ways. Sometimes this effort means large changes within the family system and also sometimes occurs in their interactions and the growth of children.

From systemic perspective, drug use by family members is behavior that disrupts the balance, stability and functioning of the family. Drugs or alcohol abuse faced family members to some challenges in emotional and behavioral functioning and ability to adjustment [10].

Family interaction of drug dependent people has a lot of tension and confusion that accompanies the negative effects of waste on children's lives. Drug users do not have good parenting skills, which provide a high-risk family environment. Poor supervision of parents on child behavior, parental conflict, poor quality of parent-child interaction, intimacy and warm words of parents, unstable or lack of discipline in such families are more common [11].

While family ties, attachment between parent and child, monitoring children's behavior, effective communication and talk about expectations and positive family values are important factors that protect family members from tendency to use drug [12].

One of the inhibiting factors for substance abuse tendency can be traced in marital satisfaction. In fact, marital satisfaction as close interpersonal relationships that allow human beings to be admitted, value, respect and be loved, and the opportunity to have interaction [13].

Hawkins and Booth are considered marital satisfaction and feeling of happiness, satisfaction and pleasure by his marriage to wife or husband in all aspects. Marital satisfaction is overall and mental assessment from the nature of marriage and the degree of satisfaction of the needs, expectations and desires of the individual. In fact marital satisfaction is a happy attitude, so it is a couple's personal attributes. The definition of marital satisfaction actually is a positive attitude and enjoyable couple of different aspects of their marital relationship [14].

In research carried out by Riahi et al, Factors that have not led to marital satisfaction of spouses are not meeting expectations, 
the involvement of others, educational and age differences and differences in opinions couples [15] and in research by zargar and Neshat doost, Problems between couples is expressed in relationship difficulties, husband addiction, family intervention, psychological disorders the [16].

In other studies, marital dissatisfaction has been attributed to emotional and physical deprivations caused by husband as a result of drug use in reducing the level of marital satisfaction and quality of life of husband and wife [17]. Skeer et al reported low income in couples who are husband addicted as a effective factor in low marital satisfaction [18]. Lavner and Bradbury reported nervousness, stress, low self-esteem and quality of violence in women with a dependent spouse and ggradual decreasing marital satisfaction. They have also shown that the couple use a similar pattern in marital relationships and life style [19].

Meltzer and McNulty, also explored less sexual relationship between couples in which the wife or both were involved with substance abuse and concluded that much less much less perception of spouse attraction that this factors have negative impact on marital satisfaction [20].

So with regard to what was stated, it can be said that the aim of this study was to evaluate the efficacy of spiritual family therapy on marital satisfaction in couples with drug dependent.

\section{Method}

This is a quasi-experimental study was with the experimental and control group. Population consisted of all drug-dependent individuals with wives in Quchan city (prisoners and patients referred to the clinics withdrawal).

To select the sample, from among the addicts their wives, of the addicts and their spouses, 40 couples volunteered to participate in this study and were placed randomly in the experimental group (20 couples) and control group (20 couples).

Selection criteria of sample for this study were 1) having the diagnostic criteria for substance use according to DSM-V; 2) patients (males) have a minimum 18 years and maximum 40 years; 3) person not be taking antipsychotics (such as haloperidol) and have not bipolar and dissociative disorder; 4) Negative urine test results and patient is completed detoxification; 5) Have the possibility to leave outside prison. Exclusion criteria included (1) Use of substances by person; (2) Each time that a participant wishes to leave plan.

After selecting the sample, the implementation of all phases of the research (pre-test, training sessions and posttest) was conducted in the Mehrafarin counseling center. Research goals were told for subjects before start of the intervention.

Ethical criteria in this study were: 1 ) To receive informed consent from all of the sample group for the study; 2) The absence of any coercion and urged or encouraged to participate in the study, 3) Participants have complete freedom to cooperation; 4) Full confidentiality of data, inventory and consultation process; 5) Nontraumatic intervention.

Afrooz Marital Satisfaction Scale Revised (AMSS-R): Afrooz Marital Satisfaction Scale Revised consists of 110 items arranged on a 5-point likert scale. The questionnaire included 10 sub titles:

1. Positive Thinking (14 questions, score range from 0-56); 2. Sexual relationship (10 questions, 0-40); 3. Personal Behavior (19 questions, 0-76); 4. Social Relationship (11 questions, 0-44); 5. Problem solving (8 questions, 0-32); 6. Financial Issues (9 questions, $0-36) ; 7$. Feeling and religious (8 questions, 0-32); 8. Parenting (9 questions, $0-36)$; 9. free time (10 questions, $0-40) ; 10$. Iinteraction (12 questions, 0-48); Total of marital satisfaction (110 questions, score range from 0-440).

An internal consistency of 0.85 was reported by authors. Coefficient alpha the scale have been reported in some studies and have ranged 0.64 to 0.86 [21]. The data were analyzed through Covariance analysis (Levene test) and SPSS-22 was used. Spiritual family therapy content based on cognitive-behavioral therapy models, made in 10 sessions and is taught by corresponding author. The content validity is approved by 
other authors of this study who are professors of psychology.Spiritual family therapy and psycho-education content mentioned in Table 1.

Table 1 Therapeutic and psycho-education content of spiritual family therapy

\begin{tabular}{|c|c|}
\hline Session & Therapeutic and psycho-education content \\
\hline 1 & $\begin{array}{l}\text { Good and create trust and security relationships with spouses, introduction to Islam's view on the importance } \\
\text { and purpose of marriage, the rights and duties of spouses. } \\
\text { Run prayer and recitation of the Qur'an and said at least one informative signs point to her husband and record } \\
\text { comments about the behavior of spouse separately. }\end{array}$ \\
\hline 2 & $\begin{array}{l}\text { Short review of the previous meeting and review homework, individual assessment and a clinical interview } \\
\text { with each of the couples in order to identify stress, personality, family conflict, family expectations, } \\
\text { expectations of each other, their thoughts and feelings. } \\
\text { Homework: monitoring the conflict, the expectations of each other, thoughts and feelings in a separate table. }\end{array}$ \\
\hline 3 & $\begin{array}{l}\text { Short review of previous meetings and review homework, self-education and cognitive differences between } \\
\text { men and women, couples education, cognitive errors, recognize emotions and negative emotions and thoughts } \\
\text { and beliefs underlying irrational and illogical explanations of the rational expectations couples from each other } \\
\text { using Islamic teachings contained in the Holy Quran and the Prophet's conduct and traditions. } \\
\text { Homework: monitoring and recording of the cognitive errors and wife separate. }\end{array}$ \\
\hline 4 & $\begin{array}{l}\text { Short review of previous meetings and review homework, review of negative thoughts and challenge them to } \\
\text { cite Quran verses and sayings of the problem and correct events, suspicion, strengthen patience and trust in the } \\
\text { Lord, praise and strengthen the ongoing relationship with the Creator. } \\
\text { Homework: monitoring your negative thoughts and his wife and registered in the table separately }\end{array}$ \\
\hline 5 & $\begin{array}{l}\text { Short review of previous meetings and review homework, training muscle relaxation and deep breathing for } \\
\text { fifteen minutes, to help couples explore ideas, to challenge negative thoughts and positive thoughts to replace } \\
\text { irrational, negative thoughts and irrational, emotional and behavioral review on logic and appealing to rational } \\
\text { thoughts, feelings and talk about them by couples. } \\
\text { Homework: to challenge irrational thoughts and cognitive errors and registration at the table }\end{array}$ \\
\hline 6 & $\begin{array}{l}\text { Short review of previous meetings and review homework, education, knowledge resources (self observation, } \\
\text { social feedback and social comparison) and their effects on relations between spouses. } \\
\text { Practice Session: Understanding the opinions of others and compare a focus on the positive and negative } \\
\text { aspects of his behavior, his wife and the couple's relationship and record of the table. } \\
\text { Homework: Sign of beliefs and behaviors associated with sources of knowledge at the table. }\end{array}$ \\
\hline 7 & $\begin{array}{l}\text { Short review of previous meetings and review homework, learning verbal and nonverbal communication with } \\
\text { respect and kindness and patience and forgiveness is based on divine commands, Practice communication } \\
\text { barriers (ordering, threatening, advise, persuade, judgment and criticism, opposition, blaming others, ridicule } \\
\text { and contempt and retaliation behavior) } \\
\text { Homework: registration of verbal and nonverbal behaviors (effective and ineffective) in table. }\end{array}$ \\
\hline 8 & $\begin{array}{l}\text { Short review of previous meetings and review homework, effective dialogue skills (expression, expression), the } \\
\text { dialogue control aggressive } \\
\text { Active listening skills (attention, pointing out, invite, summarizing and questioning) } \\
\text { Homework: Sign in using these skills at the table by himself and wife separately }\end{array}$ \\
\hline 9 & $\begin{array}{l}\text { Short review of previous meetings and review homework, education, respect, empathy and understanding wife, } \\
\text { gratitude, adornment and cleaning, gifts, cooperation in home affairs. } \\
\text { Education improvement of sexual function (cognitive differences, desires and needs) } \\
\text { Homework: practice these skills at home and record comments about the behavior of treating a husband wife } \\
\text { separately }\end{array}$ \\
\hline 10 & $\begin{array}{l}\text { Summary and conclusions with the help of a couple, program evaluation (strengths and weaknesses with a } \\
\text { survey of couples) }\end{array}$ \\
\hline
\end{tabular}

\section{Results}

Description of indicators related to marital satisfaction and components in both experimental and control groups in the pretest and posttest shown in Table 2.

The results in Table 2 shows the differences between pretest and post-test of marital satisfaction and all sub-tests were increased significantly in experimental group $(\mathrm{p}<0.05)$ while no significant changes were made in control group $(\mathrm{p}<0.05)$.

Levene test for homogeneity of variance has showed that $\mathrm{F}$ score obtained is significant (df1=1, df2=78, Sig=0.0001). Covariance analysis of marital satisfaction shown in Table 3. Table 3 shows that the level of significance in the analysis of covariance is equal to 
0.001 and smaller than 0.05 and with $95 \%$ confidence it can be concluded that there was a significant difference in marital satisfaction in experimental and control group $(\mathrm{p}<0.05)$, so spiritual family therapy is effective on marital satisfaction of couples $(\mathrm{p}<0.001)$.

Table 2 Mean and standard deviations of couple's marital satisfaction scores and its components in experimental and control groups

\begin{tabular}{|c|c|c|c|c|c|c|c|c|c|c|}
\hline \multirow{3}{*}{ Variable } & \multicolumn{5}{|c|}{ Experimental group } & \multicolumn{5}{|c|}{ Control group } \\
\hline & \multicolumn{2}{|c|}{ Pretest } & \multicolumn{2}{|c|}{ Posttest } & \multirow[t]{2}{*}{$\mathrm{p}$-value } & \multicolumn{2}{|c|}{ Pretest } & \multicolumn{2}{|c|}{ Posttest } & \multirow[t]{2}{*}{ p-value } \\
\hline & M & SD & M & SD & & M & SD & M & SD & \\
\hline Positive - thinking & 17.32 & 3.26 & 27.08 & 3.02 & 0.0001 & 18.05 & 2.09 & 18.60 & 2.73 & 0.23 \\
\hline Problem solving & 13.37 & 2.55 & 21.05 & 2.87 & 0.0001 & 15.15 & 1.88 & 15.45 & 2.00 & 0.34 \\
\hline Sexual Relationship & 16.05 & 2.60 & 25.73 & 2.73 & 0.0001 & 16.75 & 2.34 & 17.08 & 2.28 & 0.31 \\
\hline Financial issues & 13.67 & 2.67 & 23.70 & 2.62 & 0.0001 & 15.90 & 2.55 & 16.38 & 2.31 & 0.23 \\
\hline Personal behavior & 27.63 & 4.03 & 46.88 & 3.31 & 0.0001 & 28.20 & 3.42 & 28.50 & 3.25 & 0.31 \\
\hline Feeling and religious & 15.80 & 2.58 & 25.70 & 3.61 & 0.0001 & 16.60 & 3.30 & 17.10 & 1.97 & 0.18 \\
\hline Interaction & 19.30 & 2.22 & 38.20 & 3.37 & 0.0001 & 20.40 & 2.32 & 20.53 & 2.32 & 0.44 \\
\hline Parenting & 15.39 & 2.20 & 28.00 & 2.14 & 0.0001 & 17.65 & 2.36 & 17.98 & 2.27 & 0.31 \\
\hline Free time & 15.00 & 1.75 & 28.50 & 3.67 & 0.0001 & 17.40 & 2.17 & 17.73 & 2.04 & 0.33 \\
\hline Emotional (feeling) & 21.75 & 3.47 & 37.90 & 6.03 & 0.0001 & 21.50 & 2.85 & 21.98 & 2.77 & 0.23 \\
\hline Marital Satisfaction & 175.80 & 19.92 & 304.70 & 17.97 & 0.0001 & 187.60 & 17.99 & 191.30 & 18.86 & 0.13 \\
\hline
\end{tabular}

Table 3 Covariance analysis of marital satisfaction

\begin{tabular}{lccccc}
\hline Source Changes & Total squares & df & Mean squares & F & sig. \\
\hline $\begin{array}{l}\text { The interaction } \\
\text { between group }\end{array}$ & 101.701 & 1 & 101.701 & 2.066 & 0.155 \\
$\begin{array}{l}\text { and pretest } \\
\text { Group }\end{array}$ & 3065.644 & 1 & 3065.644 & 62.286 & 0.001 \\
Pretest & 13666.367 & 1 & 13666.367 & 277.666 & 0.001 \\
Error & 3740.629 & 76 & 49.219 & & \\
Total & 5196550.000 & 80 & & & \\
\hline a. R Squared $=0.986$ (Adjusted R Squared $=0.986)$ & & &
\end{tabular}

\section{Discussion}

Family is major institutions of every society and Good communication between its members is the most important factor of the health and stability of the family.

The common treatments of drug-abuse include traditional approaches such as the supportive and psychodynamic models, behavioral, cognitive, and cognitive-behavioral models. When a couple or a partner/spouse is drug abuser, family and couple therapy which use behavioral and cognitive techniques are highly efficient. Cognitive-Behavioral Therapy emphasizes psycho-education and the instruction of skills required for avoiding drug and adopting a new pattern of social and adaptive behaviors. Its major features are self-monitoring, avoiding risk factors, such as the stimuli and situations which predict drinking, changing the enforcing dependencies, instruction of resistance skills in order to fight the temptation of drug avoidance skills, problem solving, mood control, and prevention of recurrence. There also exist cognitive-behavioral strategies which can be used in family situations, and are called functional family therapies. In family therapy and functional couple therapy which use cognitive-behavioral techniques, the major assumption is that family members and their behaviors are interdependent and that the meaning of each behavior lies in the context of family system. Functional family therapy consists of a motivational component and a systematic analysis of intimate/non-intimate communicative functions which considers the application of cognitive and behavioral treatment techniques necessary [22]. They are compared the efficiency of cognitivebehavioral family and couple therapy with 
individual and group cognitive-behavioral therapy in treatment of drug abuse. Cognitivebehavioral couple therapy and cognitivebehavioral group therapy were found to be more efficient.

The method was used in this study, spirituality, family-centered therapy based on cognitivebehavioral methods have been developed and implemented. The results showed that there was a significant difference between the experimental group and the control group of marital satisfaction and all subscales (emotional, interactive, attitudinal, behavioral, supportive social, thinking, problem solving, personality, parenting, good reflection) and spiritual Family therapy was effective and affected marital satisfaction. The results of Rosen-Grandon, Meyers and Hattie [23] supported and it was approved the findings of this research.

To explain these findings, the marital satisfaction is an overall assessment of the person's current marital or romantic relationship. Marital satisfaction may be a reflection of the happiness of the marriage, or a combination of pleasing the marital relationship is due to many different factors. Can be considered marital satisfaction as a psychological situation is very unstable in the early years and relationships are at greatest risk. Given the importance of family and prevent its collapse, identify factors related to marital satisfaction is the basic strength of family life so it seems necessary, therefore, when considering the factors influencing marital satisfaction can be expected that increasing the level of marital satisfaction, is reduced many of the problems of mental, emotional, social, family and the whole society. Also, by improving the level of marital satisfaction and life satisfaction, people with greater peace of mind to the cultural and economic growth and development and social services and families will also benefit from these improvements [24].

Marital satisfaction is one of the important factors affecting women's health and life satisfaction of the most important factors that affect on mental health. Many factors affect marital satisfaction of spouses that can be educated, choice of spouse, near the cultural and economic spouses and sexual satisfaction also noted. In other hand, marital maladjustment impaired social relationships, tendency to social deviations and decline of cultural values between the couple. To sustain and strengthen family life, sexual satisfaction is an important issue and needed. The results of some studies show that the main cause of true marital dissatisfaction is lack of sexual satisfaction due to the consumption of drugs by her husband [25]. Studies on the relationship between couples showed that many emotional problems and mental disorders have psycho-social roots [21]. In the field of substance abuse were also found that four factors, low self-esteem, inability to express feelings, lack of communication skills and social impact of problem (drug use) [26]. Different studies have shown that addict families usually have a many dysfunctions and performances [26] and also lower marital satisfaction in the family [24]. Because the family functioning and relationships creates conditions for orientation to addiction, Therefore research and policy-maker in this regard could be promising [25].

The study was limited to Quchan city was the limitations of this study that should be caution in generalizing the results. It is recommended that another research done in other cities on couples involved in addiction. The findings can be used in prevention and harm reduction of drug addicts in the family and educational methods and therapeutic use for the long term used to improve the status of drug addicts.

The results showed that the spiritual family therapy using cognitive-behavioral techniques, suchas psycho-education, training coping skills, problem-solving methods, communication skills, relaxation, positive thinking, selfmonitoring, self-control, dependency-control and cognitive reconstruction, is an effective treatment for drugs dependency and other disorders resulting from it, such as anxiety, depression, and sexual malfunctioning. In this method, the therapist first identified the non-adaptive behavioral patterns which led to drug abuse, then discovered the belief system 
affecting them, and tried to change the patterns by teaching the necessary skills. One of the probable causes for the efficiency of the method might be the subjects' extreme preparedness and serious need for changing their life style. Other effective causes may be the following: the subjects' skillfulness in establishing relations, their willingness to overcome aggression, and their decisiveness and strong will for withdrawal. Other factors which might have contributed to the efficiency of the treatment method were the subjects' high social, economic and cultural status, absence of drug abuse in their original families and a history of good relationships with their parents.

\section{Conclusion}

In general it can be said that spiritual family therapy has created favorable effects and lead to increased satisfaction of couples involved in addiction and aimed at preventing relapse and reduce craving in substance abusers. The results can be the basis of family-based treatment and harm reduction interventions aimed at preventing relapse and reduce craving in substance abusers, used and re-examining it.

\section{Acknowledgements}

we are appreciated of Quchan prison staff that sincere cooperation in this research. IRCT201412052534N1 code was taken in 2014.

\section{Contribution}

Study design: MK, MM, HKA, HN

Data collection and analysis: MK, MF, RT

Manuscript preparation: MK, MM, HKA, HN

\section{Conflict of Interest}

"The authors declare that they have no competing interests."

\section{Funding}

The author (s) received no financial support for the research, authorship and/or publication of this article.

\section{References}

1- Mokri A, Ekhtiari H, Edalati H, Ganjgahi H, Nadari P. The relationship between impulsivity and risk-seeking behavior and craving in different groups of opiate addicts. Iranian Journal of Psychiatry and Clinical Psychology2008; 14(3): 258-68.

2- American psychiatric association. Diagnostic and statistical manual of mental disorders. Fifth edition. Washington, DC: American psychiatric association; 2013. 3- Ross HE, Glaser FB, Germanson T. The prevalence of psychiatric disorders in patients with drug problems. Arc Gen Psychiatry1988; 45(11):1023-31.

4- Junke GA, Hagedorn WB. Counseling addicted families: an integrated assessment and treatment model. Oxfordshire, Abingdon: Routledge: Taylor \& Francis group; 2006.

5- Selnow GW. Parent-child relationships and single and two parents' families: Implications for substance usage. J Drug Educ 1987; 17(4): 315-26.

6- Kaufman E. Myth and reality in the family patterns and treatment of substance abusers. Am J Drug Alcohol Abuse 1980; 7(3-4): 257-79.

7- Kaufman E, Yoshioka M. Substance abuse treatment and family therapy: treatment improvement protocol (TIP) Series, No. 39. Center for substance abuse treatment. Rockville (MD): Substance Abuse and Mental Health Services Administration (US); 2004. Report No.: (SMA) 04-3957

8- Soyes V, Tatrai H, Bracke R, Broekaert E. The implementation of contextual therapy in the therapeutic community for substance abuser: a case study. Journal of Family Therapy2004; 26(3): 286-305

9- Szapocznik J, Hervis OE, Schwartz S. Brief strategic family therapy for adolescent drug abuse (NIH Publication). NIDA Therapy Manuals for Drug Addiction. Rockville, MD: National Institute on Drug Abuse; 2003.

10- Ghafari F. The effectiveness of family therapy approach on differentiation and function Bowen family systems with addicted children. [Thesis]. Tehran: University of Welfare and Rehabilitation Sciences 2009. 11- Arria AM, Mericle AA, Meyersk K, Winters KC. Parental substance use impairment, parenting and substance use disorder risk. J Subst Abuse Treat2012; 43(1): 114-22.

12- Bröning S, Kumpfer K, Kruse K, et al. Selective prevention programs for children from substanceaffected families: a comprehensive systematic review. Subst Abuse Treat Prev Policy2012; 7(1): 23.

13- Safari Vesal M, Afrooz GA, Salehi M, Safari vesal $\mathrm{N}$. The relationship between characteristics of the biological, cognitive, social and emotional with marital satisfaction in parents of Autism and normal children. the first national Conference on educational sciences and psychology, Islamic Azad University of Marvdasht. Shiraz. 2014; pp:34-7.

14- Hawkins DN, Booth A. Unhappily ever after: 
effects of long- term, quality marriage on well -being. Soc Forces 2005; 84(1): 457-71

15- Riahi ME, Aliverdinia A, Bahrami Kakavand S. Sociological analysis tendency to divorce (Case Study city of Kermanshah). Journal of Women Research2007; 5(3): 109-40.

16- Zargar F, Neshat-doost HT. Divorce incidence factors in Falavarjan Township. Journal of Family Research2008; 3(3): 737-49.

1- Birditt KS, Brown E, Orbuch TL, Mcllvane JM. Marital conflict behaviors and implications for divorce over 16 Years. J Marriage Fam2010; 72(5): 1188-204.

18- Skeer M, McCornick M, Normal ST, Buka SL, Gilman SE. A prospective study of familial conflict psychological stress and the development of substance use disorders in adolescence. Drug Alcohol Depend2009; 104(1-2): 65-72.

19- Lavner JA, Bradbury TN. Patterns of change in marital satisfaction over the Newlywed Years. $J$ Marriage Fam 2010; 72(5): 1171-87.

20- Meltzer AL, McNulty JK. Body image and marital satisfaction: evidence for the mediating role of sexual frequency and sexual satisfaction. J Fam Psychol2010; 24(2): 156-64.

21-Afrooz GA, Ghodrati M. Standardization of marital satisfaction scale (AMSS) (short form). Journal of Psychology and Educational Sciences 2011; 41: 1-9.

2- Ozechowski TJ, Liddle HA. Family - based therapy for adolescent drug abuse: knows and unknowns. Clin Child Fam Psychol Rev2000; 3(4): 269-98.

23- Rosen-Grandon JR, Myers JE, Hattie JA. The relationship between marital characteristics, marital interaction processes and marital satisfaction. J Couns Dev2004; 82(1): 58-68.

24- Ahmadi KH, Nabipoor M, Kimiaee A, Afzali MH. Effect of family problem-solving on marital satisfaction. Journal of Applied Sciences2010; 10(8): 682-87.

25- Fatehizadeh M, Ahmadi A. Relationship between model of making relationship with marital satisfaction in couples. Journal of Family Research2010; 2: 110-20. 26- Feaster DJ, Robbins M, Henderson C, et al. Equivalence of family functioning and externalizing behaviors in adolescent substance abuser of different race/ethnicity. J Subst Abuse Treat2010; 38S1: S113-24.

Copyright(C) 2016 ASP Ins. This open-access article is published under the terms of the Creative Commons Attribution-NonCommercial 4.0 International License which permits Share (copy and redistribute the material in any medium or format) and Adapt (remix, transform, and build upon the material) under the Attribution-NonCommercial terms. 